\title{
Dehumanized gender identity: \\ Critical reflection on neuroscience, power relationship and law
}

\section{Chetan Sinha ${ }^{1}$}

\begin{abstract}
This article discusses the gender question which is directed towards power, whether it is family dynamics, scientific domain or another sociocultural arena. Gender was not discussed as prominently in various forums integrating neuroscience and law. The gender movement comprising feminist and queer group movement addressed various issues of prejudices in the legal domain including, the logic derived from the dominant male value system. This metatheory to critically address gender in various domains has an important role in the interdisciplinary social sciences. The context of the body in all forms were observed from the eye of the male observer rather than the eye of beholder of one's body. The genesis of one's existence in the context of gender was heavily theorised both in order to subjugate the matter of identity movement, ownership and self. Article discusses how the stereotypical view corresponding to the mythology and parasitic view prevalent in the history was made as fact through discourse construction, scientific appropriations, historical writings. Thus, identifying simplistic psychology of one's agency, societal framing of the methods of socialization and institutionalizing the common sense of inferiority about one's identity including the process of internalization along with the biological inferiority has maintained the gap in the gender equality.
\end{abstract}

\footnotetext{
${ }^{1}$ OP Jindal Global University, Sonipat. Email: sinchetan@gmail.com

Dr. Chetan Sinha, OP Jindal Global University, Sonipat

Email: sinchetan@gmail.com
} 
One of the most important and urgent identity questions is about the gender question. Answers, however, may not be sufficient as we can infer, as it is also important who is answering but how the answer is taken and understood. Some of the stereotypical view about the women showed the institutionalization of stereotypical role and character of women and their ability to deal with their emotion and external appearance, for example, "women has the weakness of being emotional or sentimental and can be easily deceived by external appearance" (in Prabhu, 1940). This prejudices about women identity are further substantiated via a number of DNA and neuroscientific evidences, which are based on the premise derived from the historical stereotypes. In both the genome and neuroscientific era, it seems that they hold dominance over the interpretations of one's identity deriving their explanations from the past stereotypes and best fitting in the present. However, the meaning of gender is also simultaneously understood critically and that also passed through different forms and narrations in different forums and contexts. Is the brain and genome static as embedded in the society? Biologist Fausto-Sterling (2010), critically pondered upon the question, 'do brain have a sex?'. She inquired about the role of biology and society in the making of gender and how 'gender becomes chemical?'. Further to the question about the gender in general it is also about the historically oppressed gender groups internalizing different gender binaries ascribed on them by society.

The interpretation of gender in terms of phylogenetic-biological characteristics of a child in terms of one's own cultural experiences (Cole, 1996) is the marker of deep-seated cultural expressions and common-sense view about the child's sense of his/her identity. This is in one way a folk psychological understanding of others in a solipsistic way which is in other word, one's own sociocultural experiences. Keil (1999) aptly stated "no one, neither child nor adult can know much of the world in much detail. We rely on a division of cognitive labour that allows us to access areas of expertise in others when we need it" (p. 181). The idea about 
the presence of any reality can also be our division of objects in terms of classes. For example, when we see colour black, the pigment is perceived by all the human who can see and similarly for white, that is all the colours can be perceived in terms of how it is collectively observed and termed and also along with its contrast or more closely opposite. In the animal kingdom human males don't compare with any other female species (as per scientific indication) but the close female human and that too appropriated with many categories operating as a moderator. We have observed things and their opposite, named them and philosophised them as duality, nonduality and so on. Therefore, philosophy is not as such in terms of perfect reasoning, something in itself and our own will and native understanding, but it is extrapolating based on what was expressed in the everyday understanding of objects, as a matter of consensus, power and hegemonizing events of one's life.

Gender is a human made construct and can be construed in either natural or as social. The image of different gender can be an emergent phenomenon based on social stereotypes and socialization. The category-based bias and stereotypes are the main regulator of judicial activism and all the corrections are made in terms of new ways of social constructions. It is not in the natural body but in the perceptions where the activism has the maximum impact. Whatever is the philosophy to know something in the sensible environment, whether conceivable or not, empirical or perceptual, gender is understood through the integration of what is happening to one's presence in the external world and the perceivers knowledge about it. This connection is non-linear and mediated by the accumulations of experiences. The notion about the object in itself or its existence in the social world directly observed via the senses of the observer has limitations and they seem to deny the ground on which these observations or quality exists (see also Smith, 2004). The brain studies were not without stereotypical notion about people from different social categories such as gender. Since gender is a sociological concept, however, it has a deep psychological impact on one's identity. There are two 
variations in the neuroscientific understanding of the brain, first, the brain structure and functions are universal and second, the brain development is laden within the sociocultural interpretations (Rippon, 2019). As it is a matter of fact that the brain doesn't say anything for itself and it is like a cog in the wheel, where the wheel is the whole system of social life. The annihilation of self which is oppressed, ascribed and insinuated with the dominant societal influence such as toxic masculinity, rejuvenates the brain from all the toxicity and generate a new identity and self. The idea behind nuclearizing the brain doesn't connect with what happened in the activities and performance and hence the experiences which is so true as it seems authentic via brain images. This article will further discuss on the following points through five subsections which are quite connected together and cover major aspects in the direction of social psychology and law. These are A) Gendered brain b) Objectifying others agency c) Gender and identity formation, d) Dehumanizing brain and identity

\section{Gendered brain}

In both the interpretations of the brain, gender of women was stereotypically understood and elaborated. Even the brain analogy was adopted as a form of attribution, where male blame their brain in the situation of benevolence, when the woman is humiliated or harassed, and on the other side female brain was blamed as oversensitive. Some of the examples like, 'Why did I humiliate my wife? I can't help myself, something happened to my brain'? This precarious masculinity or manhood (e.g., Bosson \& Vandello, 2011) overrides the menace of societal domination of patriarchy and overruled as it is within the nature of men to be aggressive. The inclining over the men's nature, their brain system and its makeup, genome system, may reproduce the stereotypical notions such as 'men's will be men's', however, it doesn't systematically override the deep-seated prejudices prevalent in our society. Whether it is the individual as a starting point of social change or at the policy level, the critique of these gendered assumption needs to be pulled out from varieties of domain where, neuroscience is 
not apart. Why in the case of male and female relationship, male blame their brain which seems to be controlling one's will to respect his wife and why the female is considered to be easily persuaded, having an emotional brain and expected to have an agency which will embrace everything from love to humiliation. And further why any kind of rebellion or assertion from the females is seen to be in the inferior positioning of the brain which doesn't understand the meaning of relationships, which is expected from her. Is it like that our brains are programmed in such a stereotypical manner? Neural firing is neural activation which is a matter of circumstances in which the human operates, but that is not enough when it comes to gender questions. The current paper directly addresses the issues of social change via countering the prevalent notions of stereotypes associated with one's gender. How the activities and abilities are associated with one's brain if the person belongs to a different gender group, can also be addressed by offering a critique to the societal notions about the persons' standing in the society. Thus, the self of a person is not hiding behind the brain or as Paul Ricoeur noted that it is also not embedded in the cerebral fiction about self which is located within the flesh (see Laughland, 2017). There were many thought experiments (see Wilkes, 1988) which either exchanged the brains and discussed the formation of personal identity or something like 'brain in a vat' (Putnam, 1981) approach. In all the cases the logic fails when simple explanations were propounded that the brain is the matter of brainhood (Vidal, 2009). It is not just the brain but the whole embodied agency of humans which construct the identity and simple reliance on thought experiments such as transporting bodies or brain will not take away the social meaning of the self, formed in the context of collectivity.

The brain is a complex neural system and this observation can be stereotypically observed in the behaviour and thinking of the person, who is also the victim of social situations. The rise of movements and critical consciousness through social activism certainly had an impact on the person and hence the person's brain. The idea is that it is not brain that decides the survival 
in the social world but the persons' social activity that survives the brain and categorizing it into inferior-superior, able-unable, logical-emotional kinds of bipolarity is the limitation of unjust social system rather than anyone's individual corporeality. It was pointed that the Kohlberg's (1981) approach in which he showed moral reasoning and normative judgments are rooted in the cognitive developmental models. It is quite established that cognition emerges from the context and it is also a matter of cultural construction (see Hepburn \& Wiggins, 2007). The assumed linear relationship between identity and cognition is taken as insufficient in explaining one's social behaviour. Similarly, the linearity between moral development and cognitive development is not sufficient to generalize at all. As Kohlberg based his study on male participants, the understanding of morality and ethics from the gender perspective was missing (see Muuss, 1988). Generalization of the process of morality on all the groups may be a limited approach, though the brain area shown to be active through scanners may show overlapping pictures when the person is engaged in higher mental processing. Some studies showed how truthfulness does not engage higher mental processes as compared to lie and deception, however, morality as per its definition is not exactly the same as telling the truth. Morality may encompass one of the behavioural components as 'telling the truth' as a matter of one's will, morality may also not deny 'telling the lie' for altruistic purpose or for greater good. For law, as its universal and ideal picture portrays, the first component of morality is better, legitimate, and pro-societal. Second aspect doesn't legitimize itself under the periphery of law and there is no willingness to affirm the need of law for greater good as it neither looks rational nor worthy enough to fit into the status of law. Telling the truth or not hiding any information when probed can have two kinds of mechanisms of understanding, one where researcher test the knowledge in an experiment with the help of fMRI or some criterial evidences such as assessment of galvanic skin response and second through the filtering of information by the available cultural templates. In both the cases, truth in actuality doesn't 
change but methodologically determined when something hidden is expressed through some channels and approved by the truth seeker. The brain itself doesn't give any firm idea about morality, truth or falsity but its sophisticated picture aligns with the researchers'/judge's schema. The whole concept of morality, truth, mechanism and methodology seems to have universal standing on authenticity but literature in the critical neuroscience and gender studies hint at something as a cultural construction. Culture is not limited, for example, masculinity with its feature which determines its essence may align universally. Gender has a moral basis and oppression of women across the culture shows the oppressive tendency of this kind of culture. Culture of masculinity in rural India where women are deprived of their right to liberty is not much apart from the women in urban areas in the similar context. Thus, gender issues are a universal issue and not a culturally limited phenomenon as understood in traditional cultural psychology. We cannot design everything in the same stereotype as some issues need to be addressed universally, since culture like gender doesn't be limited to the geographical space and the movement to address this is a global matter. When it comes to the neutrality of the brain as something determining one's identity, it must be seen in the narrow sense.

Since the brain is a good receptor of social and political views about one's physical makeup, and this systematic appropriation of one's body constructs one's brainhood. Michael Gazzaniga (2005) stated that "you are your brain" and if the brain is historically underestimated one can imagine how the agency and identity of the person is reduced on the basis of the prevalent stereotypical understanding about one's brain. Even the selfhood of the person is taken as something in the genetic makeup and brain essentialism. The Ledoux's synaptic self and Vidal' s cerebral subject deals with the significance of the brain, where the former is more about the dominance of primitive over the modern and in the latter the dominance of modern over the primitive. To elaborate on this, Ledoux model of synaptic self indicates how amygdala sends a strong emotional message (e.g., fear) to the neocortex which plays a significant role in 
information processing and cognition. Amygdala is a primitive part of the brain, have deep evolutionary capacity to survive animals from the perceived and observable threats and has strongly dominated the brain as compared to the neocortex whose influence is less strong over the amygdala inciting of the emotional response. This is similar to what David Hume ${ }^{2}$ philosophy advocated about the ethics of rationality triumphing in the context of passion enslaving reason. This latter approach in understanding the brain mechanism may attain two levels of common sense understanding which may further affect the doing of systematic sciences. First, it is the brain evolution which structure the society as it is and second it is the reasoning power of the person and so the brain to change what is stereotypically ascribed to it. If the first level is applied to the gender context, the brain essentialism is what derive the basis of one's arguments against the gender and social change, for example, if it is the amygdale which regulates one's emotions and the stereotypical assumption that females are emotional which is in the evolutionary design of the person, can also nurture the Gazzaniga's saying that 'you are your brain'. The second notion about the ethics of one's agency to come out of the regulation of passion with one's reason, is more liberating and emancipatory as it goes further to the brain essentialism and transform the meaning of the self, consciousness and the brainhood. Vidal's cerebral subject transformed human as a cultural modification of brain, as an anthropological unit emerging in modernity. It seems like a presentists' formulation of emergence of brainhood, a conundrum of self, identity and biology which is both static and moving, thus, its perennially modern. Vidal noted that the emergence of brainhood is part and parcel of the history of views about selfhood (p. 11). The way self is understood in different cultural domains, commonly across the cultures or within subcultures of broader cultural value system, emanated the idea of selfhood. The emergence of science of self-emphasized

\footnotetext{
${ }^{2}$ See Hume, David (2000 [1748]) An Enquiry concerning Human Understanding: A Critical Edition, ed. Tom L. Beauchamp. Oxford: Clarendon Press.

Dr. Chetan Sinha, OP Jindal Global University, Sonipat

Email: sinchetan@gmail.com
} 
mechanism of selves depraved it from deeper grounds and linked to the technologies such as functional magnetic resonance imaging (fMRI) for innovative meaning of self. In the context of gendered selves, the insinuation within the techniques of exploration of selves gave a concrete meaning to the prevalent stereotypes in the interpretation and dissemination into the wider social arena.

\section{Objectifying others agency}

The objectification of normality of brain in the interpretivist's framework (Dumit, 2004), which is also laden with the stereotypical notion about one's agency got its image. According to Vidal (2009) "images are offered as immediate proof that people are different because their brains are different" (p. 24). Even the structure of the language, like neuroscientific one, influence the communication pattern directs the thought about gender. Amsterdam and Brunner (2000) were indicative of Whorfian hypothesis which state that as many languages so the representative thoughts. The emergence of correlative studies in the behavioural and cognitive neuroscience has also the capacity to interpolate the common sensical way of representing the human action and intention and further metaphorize them. The same distortion based on stereotyped character, plots and histories can be reproduced in the legal domain with new culminations of metaphors and technical vocabularies. Amersterdam and Brunner (2000) gave example of this Whorfian distortion when any incident takes the form of accident. For example, the misunderstanding of the situation in the factory that the fuel barrel is empty and the worker threw still lit cigarette into that empty barrel without realizing that it still contains the traces of the fuel. The word empty had 'produced the disaster' (p. 142).

The jury or judges may either catch this term empty and the whole decision consensually approved without further thought. This may further raise the issues of culpability and inculpability depending upon the defendant's cognitive distortion and being swayed by the notion 
of empty barrel. Even the very act of throwing lit cigarette into the barrel is the act of carelessness and breeching of the factory's policy against the smoking in the factory premise. In the context of brain and gender, the subjectivities that judges hold helps in the fixing upon the keywords or phrases such as 'women are incapable to control their emotions', 'angry female leader being out of control', 'crossing the male domain' etc, may form a punchline for revivalism of assigned categories taken as suitable of marker of gender identity. These markers become the cue for decision making and spontaneously accepted as a matter of majoritarian consensus. These are the generalization of imageries we all are equipped with, the limited imagination of morality, character, body and society. Even the law is not critical of those imageries which becomes the victim of majoritarian psychology. The work in the fields of brain and cognition has also limited itself to the imageries which has a limited association with the actuality of context and mediating stimuli. Mead aptly stated that "any undertaking predisposes us to recognize and respond to those stimuli which will mediate the act. Psychologically we explain this by the presence of imagery which renders the particular stimulus in question more vivid" (Mead \& da Silva, 2011; p. 185). In the context of gender and brain, the available imageries about people from different groups, as constructed through habits and associations of stimuli, has much affected the correlatory evidence which embarked upon the brain and behaviour associations. The studies in the current times in neuroscience, is enthusiastically covering various social behaviour ${ }^{3}$ of people and their link to the brain, for example, in understanding social selves which area of the brain becomes most active (e.g. Zhu et al., 2007) and what is the possibility of perspective taking if that part or combination of brain parts is stimulated or damaged. These categories of research have ventured into the gender domain and offered neuroscientific data on the perception of people from different gender groups. Since

\footnotetext{
${ }^{3}$ Social behaviour, as per Mead (2011), can be 'readily defined as that which responds to the attitudes and movements of other individuals (p. 185)

Dr. Chetan Sinha, OP Jindal Global University, Sonipat

Email: sinchetan@gmail.com
} 
this is also the matter of what imageries researchers hold on the basis of their theoretical model and experiences which designed their research and helped in the interpretations which is alternative to the dominant imagery people hold about gender role and embodiment.

Gender has a performative role in society and this may add to the categorization of the brain into different social categories. Study demonstrated that display of organic solidarity led to experienced solidarity among the performers as compared to the display mechanical solidarity (van Mourik Broekman, Gordijin, Koudenburg \& Postmes, 2019). Judith Butler $(1988,1989)$ posited that gender is also an active embodiment which is produced and performed through bodies and language, actions, enactment and gestures (see Teo, 2015, p. 248). This showed that performance shapes the social structure. In the context of gender and culture, it can be inferred or hypothesized that mechanically situating oneself or adhering to the gender roles shapes the brain patterning and hence strengthening of the social structure. Various social movements in the context of gender led to the increased awareness and clarity about the self as biological being as well as a social being, whose connotations has been dominantly controlled in terms of one's biological predispositions only and not as a sociocultural entity. Thus, the brain is not neutral and determine force as portrayed in the scientific discourse but is socially based marker of one's activities. Reducing oneself or positioning oneself and others in brain system is a narrow way of looking the social world. Similarly, gender is not neutral positioning of self but a political one and this kind of reduction of human into different categories is a kind of political activism.

Positioning of gender as Lesbian Gay Bisexual Transgender (LGBT) group and women is a political struggle against the gender prejudice. Reduction of people into their gender category requires resistance via same category to counter it. How can thus a brain be neutral to gender? If someone is prejudiced based on one's sex and socially constructed via the established gender rule, then the positioning of one's identity into one's brain is not science but pseudoscience 
and completely a prejudice in action against the people of historically oppressed gender group. The development of feminist movement has undertaken all the existing stereotypes from biology to social critically (Henriques, Hollway, Couze Venn \& Walkerdine, 1984). Following this movement against the prejudices of gender identity has also given major blow to the neutral looking male dominated science. As there was major resistance to the neutral looking scientific theories, the coming of phenomenology shaped through the social circumstances has got the revival against the dry empiricism and observation from the unquestioned male lens. This majoritarian view often got threatened with new observation and subjectivity from within the neuroscience domain and offered a fresh perspective to critical venture into the established ideas of brain and behaviour. Gender got its armoury from the metatheory of critical consciousness and gave a road to venture into the science of humanity. The notion that structures determine its content is a limited account of human agency as in the context of gender. This implies a core of cognitivism which dependent upon the structure and thought. In the case of physical structure, the counting of the brain as a marker of one's inferiority or superiority is a misplaced idea and contrary to the agenda of social change. Thus, essentializing the neuroscience uncritically is contrary to the reality of social movement that happened and crossed the boundary of determinism.

Self and body and its changing relationship with new movements and interdisciplinary flux has challenged the essentialist ideology of fixing categories based on one's history and nature. The mutative line of existence in the context of gender with new inputs of desire, relationships, observations, and dialogues move beyond the essentialized nature of ascriptive self. This is all happening in the performance and activities and hence loaded in the experiences of brain. Neuroscientist noted that these self-referential information process activates the specific brain areas such as dorsal and pregenual anterior cingulate cortex (dACC and pACC) in the medial prefrontal region, insular cortex, temporal-parietal junction, the extrastriate and fusiform body 
areas (EBA and FBA) (e.g., Northoff et al. 2006; Craig 2010; Blanke et al. 2005; Vocks et al., 2010; see also Majid et al., 2020).

\section{Gender and identity formation}

Gender can be viewed from two vantage points, one from the actors' perspective, who is living the gender in both its ascriptive and experienced form and second from the observers' perspective, where someone's physical structure determines the whole gamut of person identity. In the first case, sometime the dominant societal notions become more pronounced in the self-judgement rather than the person's own capacity to willingly shape one's identity. Neuroscience's incapacity to discuss these issues which are very well operating under our nose shows the reductivist stand without any movement which can move the debate further. Though some of the research tried to culminate the understanding taken from interdisciplinarity between neuroscience and social science, the gap remains much pronounced and this compels majority of critical social scientist to ignore the brain science in their active discussion of social identity, gender and bodily self. In the process to rework on the gender and identity formation, the bifurcation of self as a matter of emergence of consciousness in the varieties of contexts can't be separate as it seems. It is the self in the context which situates the sociality of the person. For example, the women right activist cannot dramatize their life into varieties of social space in a way completely different in different context, as a spouse, as an activist, as a parent and so on. The criticality towards power structure will intervene in those contexts stamping them as women right activist in true sense. The way our selves are shaped is a movement of desire, history, politics and economy. Gender is more or less one's self, as James stated in terms of, pure and empirical ego. Pure ego is more phenomenological and subjective, however, it may be translated as either perception of the objective world or something qualitatively inexplicable to the other in the popular vocabularies of society. Empirical ego is what society 
gives the person, a category and vocabulary to describe, act and situate in an immediate context. In the similar terms gender better equips itself within the periphery of empirical ego, where social structure and societal norms are embedded in one's roles and activities. The clash between these two egos may be a possibility where the second one strives and thrive over the more inert and subjective one. The vocabularizing of subjectivities call for a movement and gives shift to the prevailing prejudices. How come the brain is not involved in these processes, seems to be the poverty of neuroscience which doesn't have a proper theory to engage with the future of societal shifts. The meaning of gender in these two ego forms show that one has the self for which the person may or may not have control, however, the bodily makeup doesn't give a person freedom to change it but the person's perception and attribution may get changed with the alterity and identity intersections. The shifts in the identities and self, demand new avenues of social change where feeling, emotions, perceptions and consciousness gets new meaning. Ledoux (2002) noted,

"Neuroscientists have been quite successful in figuring out how pieces of the brain puzzle work (perception, movement, learning, emotion) but have not made much progress in putting the pieces together to build the kind of global picture of brain function that would be necessary to understand how one's personal identity, one's self, is represented in neural tissue" 4 .

Further to this assertion, neuroscientists' reductionist account of human behaviour provided atomist view of human relationship which possibly drove its explanations from the evolutionary theory. In that case, the limited account of identities, both personal and social, where only managed in the brain terminologies which is important and necessary, however, doesn't cater to the lived-in experience of people which gets translated with new complexities

\footnotetext{
${ }^{4}$ Ledoux, J. (2002). The self and the brain. Prospect. Retrieved from: https://www.prospectmagazine.co.uk/magazine/theselfandthebrain

Dr. Chetan Sinha, OP Jindal Global University, Sonipat

Email: sinchetan@gmail.com
} 
of identities. The idea of neuroscience can contest the point of origination of human behaviour, which they deem fit to be in the brain rather than any assertion of social scientist. The debate hence continues until a point reached where social context and brain neural firings comes together in enriching the accounts of human thought and behaviour together. The self of the person explained at the personal identity level is more straightforward, as in the work of R. D. Laing, where the persons who have some psychological disorder seen in the person's social activities construed or distorted into divided self, where "images of the child is of someone constantly facing the task of self-creation on the basis of available evidence" (see Richards, 2009; p. 250). For example, he traced psychopathological disorder "to the social dynamics of the family during childhood where children create their identities from the messages received from those around them". If these messages "are contradictory or confused they are driven to increasingly bizarre lengths in trying to understand what is going on" (see Richards, 2009; p. 250).

Any neurological deficit, for example, in the language area of the brain, may identify the person as linguistically deficit and his/her identity get defined by these terminologies. In one way this kind of approach is to overcome Cartesian dualism, as Chomsky (see Katz, 2012) ${ }^{5}$ critically noted the rise of unification of the brain and cognitive sciences. How come this integration of brain and cognitive science will debunk the established theories on intelligence and other cognitive superiority of one over the other? The straight correlation between brain functioning and outward behaviour had simplified the understanding of human social relationships. It is other way of theorizations from the critical perspective or from the approaches of diverse identities who intermingle with their environment in cultural divergent

\footnotetext{
${ }^{5}$ Katz, Y (November 1, 2012). Noam Chomsky on Where Artificial Intelligence Went Wrong: An extended conversation with the legendary linguist. The Atlantic.

(https://www.theatlantic.com/technology/archive/2012/11/noam-chomsky-on-where-artificial-intelligence-wentwrong/261637/)

Dr. Chetan Sinha, OP Jindal Global University, Sonipat

Email: sinchetan@gmail.com
} 
ways, outside the understanding of majoritarian and mainstream view, may offer beyond the boundary explanation of this interdisciplinarity. In other words, the prevalent stereotypical connection between brain and cognitive sciences, without construing that the prevalent gender stereotypes can also be coming into the new science discourses in more formal manner, in the established terminologies to be forced upon or taken by people across the different social groups. The standardization of gendered way of doing neuroscience is uncritically making its way in to the courtroom. Though the series of research in neuroscience contested the stereotypical way of understanding gender, by taking diverse population into the fMRI scanner, still the neuronal circuits underlying gender identity are unknown (Majid et al., 2019). However, Majid et al. (2019) compared the "brain activation and connectivity in transgender individuals (for whom gender identity and birth-assigned sex are incongruent) with that in cisgender controls (for whom they are congruent) when performing a body self-identification task during functional magnetic resonance imaging, they showed that transgender individuals identified with images morphed "opposite" to their birth-assigned sex" (p.1). They showed that the activation of self-processing brain network is specific to gender identity rather than birth assigned sex (p.1).

The developmental theories indicate the universalized mechanism of physical, cognitive and social development of the child, however, how this development happens in a cultural context and among the diverse group is understated. Law is a designed and symmetrical way of ascertaining rules made through the consensus at varieties of levels. If any debate made by the experts of neuroscience or developmentalist gets affirmed by the legal community, it creates discourse based on those appropriations, rather than on the basis of critical literature showing the alternative interpretations of data and evidences from the dissensus framework. Dissensus framework, as stated by Kraus (2012) is "a critical framework centred on the study of conflicts and controversies, including their absence, unsuccessful controversies, etc" (p. 193) 
(for example, critical developmental perspective or critical neuroscience perspective). As Kraus (2012) aptly questioned "which is the most important sex organ for gender identity formation in intersex people: their brain or their genitals?" Now, this question can be answered in different disciplinary perspectives. Let's us keep it as biological and social, where biological perspective strengthens its view via physical stature of the person, as what is in the genetic make-up, hormonal and species typical behaviour. Social view conjures towards one's perception of self and identity, social relationships, everyday linguistic display in a social context, group behaviour etc. The combination of these two perspectives is also possible and some social psychologist showed the importance of integration in the better explanations of identity question (e.g., Jetten, Haslam \& Haslam, 2012; Matheson \& Anisman, 2012; Henriques, Hollway, Venn, \& Walkerdine, 1984). Neuroscience, as Krauss, speculated has the potential to enlighten the medical gaze of sexuality and make it more scientific (for example Majid et al, 2019), however it is more inclined to the biological side and brain is the foremost organ to deal with the question of gender identity. The given explanations in the neuroscience where brain responds to different cues in the environment pertaining to one's recognition of gender identity as social one or biological one, show the enlightening picture of neuroscience. Some scholars see biological marker as a source to understand culture (Fausto-Sterling, 2010). Fausto-Sterling noted that,

"it seems that in the genomic era biological information holds greater power over identity development than genealogical and historical documentation, or oral and cultural tradition" (P. 168).

The indication is towards the rise of science through gene and neuroscience and attempt to connect them with group membership. From Fausto-Sterling (2010) account it is clear that the DNA and other biological variants such as neuroscience is taken as fixed among the determinists circle. There is no doubt that people will be having same Deoxyribonucleic acid 
(DNA) throughout and associating it with the group membership such as gender is contrary to the idea of social identity which demands social change. The current literature on social identity and brain try to cross over the incompatibility where the former is a matter of shift within the social context with new ideas, meaning of self, memories and activities as compared with the brain whose structure are well defined by the neuroscientist as intact. The resolution of incompatibility with new perspective connects social and identity and brain as operating in the context in a holistic manner. This itself transform the inherent duality that nurtured the idea of human body and mind through critical philosophical positioning. Even if the perspectives shift, the observations show that human change with the time, which gives immense weight to the idea that future of the brain is not fixed but open up new avenues of explorations. The problem with the current account of biology comprising the DNA based studies of human behaviour is the 'lack of developmental perspective' to understand identity formation (Fausto-Sterling, 2010). However, Fausto-Sterling (2010) referred to the researcher who propounded the term gender identity, John Money, emphasized the high degree of malleability or plasticity in gender identity formation in the earlier years (Money \& Ehrhardt, 1972) before it gets fixated with age maturity. Some scholars noted that it is hormonal influence on the brain which decided the sex of the brain which eventually direct development into male and female gender identity (e.g., Daimond, 2000; see Fausto-Sterling, 2010), however they don't have direct evidence in the gender identity formation.

Fausto-Sterling (2010) explained this through a study which reviewed the cases of 46, XY children with cloacal exstrophy (rare birth defect in which infants are born without external genitalia and with other malformations of the bladder and surrounding tissues) (see Byne et al., 2012). These children were assigned and raised as either girls or boys. Most of the patients who were assigned female identity (33 out of 51) lived as female at the time of study, however, some are living as male (11 out of 51) and few expressed their wish to become male (7 out of 
51) (Fausto-Sterling, 2010, p. 171). It was also shown that 'male raided 46, XY patients, in all age groups, lived as males' (p.171) indicating that data based on prenatal hormones, genetic or other factors do not correspond completely to gender identity, thus, critically debunking the role of full biological determinism. There are studies which showed in the post-mortem of male to female transsexuals (MtF) that their hypothalamus in the brain resembled as female which was taken as evidence for biological cause of this gender identity preference (e.g., Kruijver et al., 2000; Zhou et al., 1995). Lawrence (2010) added to the research substantiating that there is a feminized brain among the MtFs causing their desire to change their anatomy to fit the preferred gender identity, however, earlier these aspects of one's preference were seen under the category, gender identity disorder of childhood (GIDC) of DSM (1980), if observed among children. Among the feminist scholars of psychology, it was advocate that understanding body is a need to conceptualize subjectivity, in other words, subjectivity has a prominent relationship with one's bodily self(e.g., Stam, 1998; Bayor \& Malone, 1996; cf Teo, 2015). The subjugation of the body has a direct relationship with the subjugation of self and subjectivity. The demeaning and reduction of one's subjectivity into inferior or superior body structure and brain, reconstruct one's subjectivity either as accepting to the social stereotypes towards oneself or forming a rebellion along with the people who are also undergoing similar kind of emotions. This whole process of acceptance and rejection of ascription as inferior brain, based on stereotypically loaded gender identity shows the power dynamics inherent in the societal structure manifested in the activities and culture of different social groups. The formation of gender identity can also be the result of looping effect (Hacking, 1994; see Teo, 2015) where the individual interacts with the assigned psychological categories, form impression of their self through the observers' eye and internalize it as part of their subjectivity. Gender identity formation starts with ascription based on the sex and the socialization in that direction. Though research showed how the meaning of identity in terms of the ascribed sex and latter realization 
with new alterity witness the shift in self-understanding, the bodily framework is a prominent marker of one's social identity when it comes to female corporeality. However, gender minorities raised their voice against the politics of ascription, and advocated their will to go beyond the stereotypical labelling, they are more susceptible to the epistemological violence, where identity is negatively described and taken as fact about the people from gender minority group. This countering of the ascribed psychological categories by gender minorities through social movement is a new way of contesting with the given self, in other words, a new kind of psychologization and reconstruction (Teo, 2015). In the social identity vocabulary, this can be the process of de-categorization, re-categorization and reconstruction of novel identity due to the felt permeability to the earlier impermeable social boundaries.

\section{Dehumanizing brain and identity}

Graham Richards (2009) cited the work of C. Lombroso and W. Ferrero on 'the female offender' published in 1895 , where he depicted the picture of female offenders reduced to 'anomalies and asymmetry in cranial morphology' such as 'female criminals are hairier, have more warts, less symmetric faces and weightier jaws than their law-abiding sisters' (p. 263). This was dehumanizing, where both reducing them less than as human and making them as a victim of epistemic violence. It showed a powerful depiction of stereotypes one holds about others in terms of these women criminal embodiment making it as part of their psyche, further strengthened through the dehumanizer's confirmation biases. Snatching all tints of humanity, disregarding the plights of poverty, humiliations, and brutalities inflicted on these women, it was all the medical appropriation of one's human agency. Law, as a progenitor of societal morality, felt short of that understanding which was needed to provide justice, at least biological justice. The construction and reconstruction of bodily biases created or psychologized the people mind with these ascribed categories which acted 
like a template for filtering out any humanness in the name of law which considered itself as neutral, legitimate and morally righteous. The difference between primitive and civilized representations (e.g., Moscovici, 2001), seem to be loaded with gender-based stereotypes in the latter than the former. The coming of the modern times was the oppressive engagement with nature and the worldviews about the women was exploitative rather than nurturing or accepting. The impeccable view about the male was exploring, creating, developing and able as compared to women who was better considered to be suitable for nurturing child and family. Even the female body was acceptable under the normative. Any divergence rendered her outcasted from the irresistible gender-role nexus. The question which needs to be addressed here is how the advocates of gender summarised male and female psychology and locked it into some fixed binaries. If we observe group of people swimming, this observation will be same for all, however the subjectivities may be different loaded with the memories and desires. The critical notion which addresses to the concern that whether we need distinct male and female psychology (Richards, 2009) has to be seen under the new format where identities need to have a balancing view. The assertion of one's identity based on the collective memories is as much needed as the need to see the world from more improved platform of social justice. The differences and similarities together make the theory better.

There are studies which noted the neural correlates of cognitive objectification (Bernard et al., 2018; Bernard, Gervais, \& Klein, 2018) and how sexualized bodies, body movements and postures signify the women mind and objectification of their agency (Bernard \& Wollast, 2019; Lamb \& Koven, 2019; Vaes, Paladino \& Puvia, 2011). Bernard and Wollast (2019) noted how "sexualized people are perceived as possessing fewer traits of human being". Just by the suggestive posture impression, women were objectified and perceived as less moral as compared to women in the non-suggestive posture. As identity is not a 
static category but the formed impression through different contexts, both body posture, group affiliation and routine activities, fixes the identity making the people more vulnerable to prejudices and dehumanization. In the context of gendered brain, it is also pertinent to look at the gender identity within the class hierarchy. In any economy where there are perceived inequalities as well as the true socioeconomic status differentiations, the biology of the person has a double impact, especially in the case of gender minority who face the double impact of both sex and the social class-based stereotypes. How the brain of the person of minority gender identity be seen as operating in a neutral manner? In the case women whose child was prone to schizophrenia symptoms, were blamed for their parenting. The coming of biological-neural association for schizophrenia had freed women from internalization of blame and culpability as a schizophrenogenic mother. But at the same destined her to the grand labelling of being unfit mentally with the deficit brain. This is also one kind of dehumanization in the field of psychopathology where the brain deficit mother has to bear the double brunt of being an unsuccessful mother together with the neurological deficiency. The misunderstanding between the biological susceptibility and biological determinism led to a number of stereotypes emanating out of flawed biologysociality nexus where cultural factors were hardly accounted (see Luhrmann \& Marrow, 2016).

In the context of understanding other mind, social neuroscientist showed how stigmatized group doesn't elicit neural activities 'necessary for understanding other minds' (Fiske, 2009). Generally, it is embedded in the stereotypical impressions that the capacity to understand others' mind is actually a human activity and only somebody less than human lack that capacity. This is a dehumanization tendency to take the brain route to systematically prove that people from particular group(s) lacks the neural capacity to understand the others mind. The theory of mind (tom) approach in which the person forms 
a cognitive impression and predicts about the others mind can also be solipsistic. The reliance on consensus may not give the true picture of what one think about the other unless complemented with the neuroscience approach. However, the need for radical rationality in the overall attribution and interpretations of the neural activities linked to the gender identity, may be both relieving and degrading. For example, the interpretations about the women agency, prescribed activities and requirement to be part of any institutions such as marriage, through the available legal lens or texts such as different code of conduct (Hindu Code Bill and Sheriya Law) is based on the societal norms constructed in the history through the intervention of dominant group and systematic exclusion of the marginalized and women.

The appropriation of these historical knowledge as scientific knowledge embedded through the confirmation biases and ignoring what relieves the marginalized from the shackles of wrong attributions, showed the demeaning and devaluation of one agency as volatile, movable and congruent to the idea of social change. Science itself is a movement where new observations changes or add to the previous theory, what Karl Popper (1968) stated as the marker of scientific approach. The confirmation biases in science and social science interdisciplinarity give way to pseudoscience, and all sciences, which generalization the basis of few observations may not be true representative. However, if science liberate the marginalized from the wrong attribution and historical misunderstanding both in the laboratory and public domain has the potential to be social change oriented. It can be also the case that two categories of observation, one from the brain activities and other from the general understanding of other, may co-vary resulting in the immediate association and impressions. Association is one of the most surreal experience which may not be based on true logicality, it may be providing the comfort seat into one's already accepted domain. Neuroscience when associate with gender have the 
greater chance of getting subsumed by the gender-based expressions and interpretations laden in beliefs and culture. Rippon stated that "so our brains are not just being changed by concrete data about sights and sounds in the outside world, or by very specific experiences and events; they are actually absorbing and reflecting the attitudes and expectations of those around us" (P. 140). Though these attitudes and expectations work differently for different gender groups. They operate both dispositional and contextually depending upon the social category positioning in the society. Harris, Todorow and Fiske (2005) noted that other person's perceived disposition is one of the frequent reasons for the prediction of behaviour and action as compared with the social norms. This was further validated through the brain studies where activation of brain areas such as superior temporal sulcus (STS) and medial prefrontal cortex (MPFC) happened during the low consensus conditions. These areas of the brain are responsible in attribution about others dispositional characteristics such as unique attitudes, personality, and idiosyncratic intent, in the high consistency situation.

As we process various kinds of social information, it will be simplistic to generalize that general social cognition which neglects consensus information, is a human nature. Our engagement with various social and culturally based information is also the matter of our socialization, repetitive engagement with the social content and stimuli which are essential in the construction of our consciousness and meaning making. It can be inferred that the social context plays an important role in framing attribution about self and others. In the cultural context where patriarchy shape the dominant value system, attribution towards marginalized gender group is more towards the inner psychological disposition such as character and traits. Here the latent distribution of prejudicial intent operates in a subtle manner against the marginalized gender group, though its outward manifestation, as it was seen in implicit stereotyping studies, where social behaviour was found to be operating in implicit and unconscious way (See Greenwald \& Banaji, 1995). Some of the studies 
showed how gender stereotypes are implicit, for example, essays having male author names were judged more favourably than the female authors name (Goldberg, 1968). Greenwald and Banaji (1995) viewed that this kind of judgement show a gender stereotype that categorize males as with greater achievement then females. In other studies, it was noted that mere presentation of traits (e.g., aggression vs dependence) categorised people as male or female showing how implicit stereotyping is automatically manifested in the behaviour and action (Banaji, Hardin \& Rothman, 1993). This is quite evident in our everyday life where we engage in mini experiments to test our and others behaviour and even if these establishments of cause and effect is not so laboratory based, we get the sense of ourselves and others about the characteristics, behaviour, stereotypes and the way any one is dehumanized. We have witnessed both false alarm and the hit when we feel our cognition congruent or distorted by our preconceived notion about the others. Sometime people behaviour fit to the available stereotype and sometime mismatch like a Wittgensteinan beetle box (see also Murphy, 2020) ${ }^{6}$ which we thought has a beetle in it. It seems like whatever prejudice people hold against the marginalized, if not made conscious (as it was shown in the experimental studies), they express it in the form of behaviour, sometime as a kind of discriminating act. If made conscious or asked to focus on their act, the chances of implicitly falling into discriminating action may be reduced. Since there are many kinds of social groups in our society and are emerging in different permutations and combinations in different situational context, it becomes hard to be linearly focussed towards one's attitude towards different social group. Unless their social position, status and history is mobilized in the form of public discourse through the different channels, it will be limited to the experimentations in the laboratory. The culture and biology may form a unique

\footnotetext{
${ }^{6}$ https://medium.com/@paulaustinmurphy2000/wittgenstein-on-the-beetle-in-the-box-and-the-beetle-inyour-mind-58c95eaf6ff2

Dr. Chetan Sinha, OP Jindal Global University, Sonipat

Email: sinchetan@gmail.com
} 
discursive combination which have a direct effect on the people social relationship. The dehumanization of people from marginalized gender group such as women on the basis of brain is a new form of biologism where the propensity of one's agency to be in the better position is largely reduced with this kind of scientific upheaving. In the society where emotion is connected to gender and there is straight judgement about the authenticity of emotions, for example, interpretations of females and male expressing emotions and the way it is taken as true. The very act of the person injuring the other gets its social shots when it comes to the interpretations and it is quite laden within the available consensus. The way male leaders express their emotion as compared to the female leader, where chances are high that the former is going to influence the larger audience in the public domain. This is further influenced by the social class of the person which plays an important role in the interpretations of available cues, both neural and social.

In one of the studies on dehumanizing representations of women, Tipler and Ruscher (2017) suggested that the "continued transmission of animalizing metaphors for women may help perpetuate prejudicial beliefs about appropriate roles for women in society" (p. 109). These animalizing metaphors which animates from the social structure led to dehumanization and dementalization where the former degrade the human agency to animals and latter involves the denial of a person's human essence, nature and experience (Gray, Gray \& Wegner, 2007; Haslam, 2006; see Tipler \& Ruscher, 2017). In one of the neuroscientific studies, Cikara, Eberhardt, and Fiske (2011) observed that participant with the high hostile sexism scores elicited less activity in brain areas responsible for social cognitive processing and mentalizing, that is, medial prefrontal cortex (MPFC), temporoparietal junction, praecuneus/ posterior cingulate, superior temporal sulcus, and temporal poles (see Frith \& Frith, 2003; Mitchell, 2008) in comparison as compared to sexualized men or clothed women (P.4). This showed how the context and way of seeing gender in 
stereotypical way can result into dehumanization. Though, Tipler and Ruscher (2017) noted that there is "no gender differences in the impact of animalizing metaphors on attitudes towards women" (p. 111), it also matters how people internalize the social system and adopt the patriarchal gaze in the process of assigning meaning to the others agency. So, it is also a matter of adopting a critical gaze at the collective level to counter already acquired and ascribed worldview about seeing the marginalized identity or countering what was internalized by annihilating the given marginalized identity. It is observed that the movements against the rigid gender hierarchy had led to the changed discourses and gaze towards the marginalized self and others, and if this is happening, then brain is not a part of it. This may further lead to the inverse process of dehumanization (see Waytz, Epley \& Cacioppo, 2010) where people treat human as animal or object having positive quality straight away raising the levels of human when labelled. For example, this woman is like computer as we see in the case of Shakuntla devi, the famous mathematician from India, or 'this woman is brave like lioness' or 'this girl sings like a koel' and so on. Sometime people dehumanize their object of use whom they like, for example, computer, android, vehicle or in some case give personhood (for example, assigning human name) to the pets. In the context of medical examinations, it was noticed that patient whose body x-ray image was seen by the doctor has less human concern as compared to examination of computergenerated image along with the patient photograph. This is one of positive sign where there is dehumanizing of the person to images and then re-humanizing with the accompanied photograph. What if the doctor sees the x-ray report of males and females? May be when not accompanied by the photograph, a better equality can be attained. Dehumanization having positive connotation is less than common as compared to derogatory labelling and possibility of infra-humanization and devaluation when compared as equivalent to female $\operatorname{dog}$. 


\section{Conclusion: Brain, gender and social change}

In order to develop a better space for understanding, this dehumanizing tendency and other of marginalized group such as women and people from other binary group has a grave consequence for them as compared to similar kind of labelling used to dehumanization of males. In the former case, it creates the emotion of shame and humiliation and in the latter case aggressiveness and anger. Though this kind of dehumanization creates aggressive emotion among female group also but its manifestation is within the ambit of humiliation and suppressions. Sometime the status of women is raised by subscribing it to the male attributes, which can be seen as social creativity, but at the same time it shapes the agency of women as male agency. What neuroscience can do about these things and how law may intervene in order to eliminate these animalistic metaphorization and objectification of minorities and marginalized gender group? There are suggestions to counter one's deepseated biasedness against the minority, which has both neural intervention and social one. The strategies to enhance ACC-mediated conflict monitoring process along with the consciousness directed towards the cues that facilitate the control (e.g., Kleiman, Hassin, \& Trope, 2014; Monteith, Ashburn-Nardo \& Voils \& Czopp, 2002; cf. Amodio, 2014; see also Fiske, 2009). What about the intervention to address the implicit biasedness and expression? These strategies are predicted to control the implicit stereotypes but the chances of sleeper effect can't be denied as the person from dominant group such as male may encounter biased kind of mobilization from peer, media, or everyday encounter rigidifying the once diluted prejudices. The best strategy is the facilitation of social movement and encouraging the critical alterity from the gendered group such as women and LGBT enhancing everyday dialogue which has potential to counter the prejudice in 
better way. Thus, the positive intergroup contact fosters the sense of inclusiveness and construction of new social identities (Reimer, Kamble, Schmid, \& Hewstone, 2020).

In conclusion, the strategies to counter dehumanizing others, who are marginalized, on the basis of their brain structure and functioning need to be corrected at the perceptual level. This is possible with the enactment of pro-diversity and unconditional acceptance of the person from marginalized gendered group. Even the likeminded group of people who challenges the social ostracization on the basis of gender may reach up to the level of amelioration, instead of complete social change and transformation. This logical poverty to stand the trial of understanding and accepting others may fail the agenda of construction of common identity. The effort to bring the element of inclusiveness is sometime same as bringing change but on the terms of dominant group, unless overhauled through what John Shotter (2011) called for emancipatory positioning of the self. It is in 'embodied anticipation and expectations' through which we integrate our understanding of the world. Shotter called this as an 'orientational' understanding. If this understanding about the social world brings incongruency in the self, the chances are high that the self is marginalized and has located itself within the ambit of dominant values. The congruency of the self with the external world where what was earlier perceived to be the case of oppression, is now perceived as inviting, emancipatory and liberating in a 'way of being in the world' (Shotter, 2011). The hardest part, however, is to crack the deep-seated worldviews that has occupied the mind of the society. All the new effort to bring change in the mindset and attitude against the gender prejudice that are not fact, except the prejudice itself, gain fuel from the different dominant perspectives that had directly formed association with the actions and observations in various social domains. For example, subjugation of the women in family in various forms, in occupation, in everyday interactions gives a prejudiced high for the dominant groups. The association of subjugation of women to evolutionary theory (see 
Fausto-Sterling, 1992) and substantiating with the quirky observations and populist theory on smartness, superiority and inferiority of genes, uncontrollable hormones, physical fragility, and size of the brain, has no doubt dehumanized marginalized gender group and kept them below the standard of human being.

\section{Abbreviation:}

fMRI: functional magnetic resonance imaging

LGBT: Lesbian Gay Bisexual Transgender

dACC : Dorsal Anterior Cingulate Cortex

pACC): Pregenual Anterior Cingulate Cortex

EBA: Extrastriate Body Areas

FBA: Fusiform Body Areas

DNA: Deoxyribonucleic Acid

$\mathrm{XY} / \mathrm{XX}$ : Sex Chromosomes

MtF: Male to Female Transsexuals

GIDC: Gender Identity Disorder of Childhood

DSM: Diagnostic and Statistical Manual of Mental Disorders

STS: Superior Temporal Sulcus

MPFC: Medial Prefrontal Cortex

\section{References}

Amodio D. M. (2014). The neuroscience of prejudice and stereotyping. Nature reviews. Neuroscience, 15(10), 670-682. https://doi.org/10.1038/nrn3800

Amsterdam, A. G., \& Brunner, J. (2000). Minding the law. Cambridge: Harvard University Press.

Banaji, M. R., Hardin, C., \& Rothman, A. J. (1993). Implicit stereotyping in person judgment. Journal of personality and Social Psychology, 65(2), 272.

Bayer, B. M., \& Malone, K. R. (1996). Feminism, psychology and matters of the Body. Theory \& Psychology, 6(4), 667-692.

Dr. Chetan Sinha, OP Jindal Global University, Sonipat

Email: sinchetan@gmail.com 
Bernard, P., \& Wollast, R. (2019). Why is sexualization dehumanizing? The effects of posture suggestiveness and revealing clothing on dehumanization. SAGE Open. 9 (1), https://doi.org/10.1177/2158244019828230

Bernard, P., Gervais, S. J., \& Klein, O. (2018). Objectifying objectification: When and why people are cognitively reduced to their parts akin to objects. European Review of Social Psychology, 29(1), 82-121.

Bernard, P., Rizzo, T., Hoonhorst, I., Deliens, G., Gervais, S. J., Eberlen, J., ... \& Klein, O. (2018). The neural correlates of cognitive objectification: An ERP study on the body inversion effect associated with sexualized bodies. Social Psychological and Personality Science, 9(5), 550-559.

Blanke, O., Mohr, C., Michel, C. M., Pascual-Leone, A., Brugger, P., Seeck, M., ... \& Thut, G. (2005). Linking out-of-body experience and self processing to mental own-body imagery at the temporoparietal junction. Journal of Neuroscience, 25(3), 550-557.

Bosson, J. K., \& Vandello, J. A. (2011). Precarious Manhood and Its Links to Action and Aggression. Current Directions in Psychological Science, 20(2), 8286. https://doi.org/10.1177/0963721411402669

Butler, J. (1988). Performative Acts and Gender Constitution: An Essay in Phenomenology and Feminist Theory. Theatre Journal, 40(4), 519-531. doi:10.2307/3207893

Butler, J. (1989). Gender trouble. Feminism and the subversion of identity. New York: Routledge. Byne, W., Bradley, S. J., Coleman, E., Eyler, A. E., Green, R., Menvielle, E. J., ... \& Tompkins, D. A. (2012). Report of the American Psychiatric Association task force on treatment of gender identity disorder. Archives of sexual behavior, 41(4), 759-796.

Byne, W., Bradley, S. J., Coleman, E., Eyler, A. E., Green, R., Menvielle, E. J., ... \& Tompkins, D. A. (2012). Report of the American Psychiatric Association task force on treatment of gender identity disorder. Archives of sexual behavior, 41(4), 759-796.

Cikara, M., Eberhardt, J. L., \& Fiske, S. T. (2011). From agents to objects: sexist attitudes and neural responses to sexualized targets. Journal of cognitive neuroscience, 23(3), 540551. https://doi.org/10.1162/jocn.2010.21497

Cole, M. (1996). Cultural psychology: A once and future discipline. Harvard University Press. Craig, A. D. (2010). The sentient self. Brain structure and function, 214, 563-577. 
David, H. (2000 [1748]). An Enquiry concerning Human Understanding: A Critical Edition, ed. Tom L. Beauchamp. Oxford: Clarendon Press.

Diamond, M. (2000). IV. Sex and Gender: Same or Different? Feminism \& psychology, 10(1), 46-54.

Dumit, J. (2004). Picturing personhood: Brain scans and biomedical identity. Princeton and Oxford: Princeton University Press.

Fausto-Sterling, A. (1992). Myths of Gender: Biological theories about women and men. Ney York: Basic Books.

Fausto-Sterling, A. (2010). Biology and identity. In M. Wetherell, \& C. T. Mohanty The SAGE handbook of identities (pp. 165-185). SAGE Publications Ltd, https://www.doi.org/10.4135/9781446200889.n10

Fiske S. T. (2009). From dehumanization and objectification to rehumanization: neuroimaging studies on the building blocks of empathy. Annals of the New York Academy of Sciences, 1167, 31-34. https://doi.org/10.1111/j.1749-6632.2009.04544.x

Fiske S. T. (2009). From dehumanization and objectification to rehumanization: neuroimaging studies on the building blocks of empathy. Annals of the New York Academy of Sciences, 1167, 31-34. https://doi.org/10.1111/j.1749-6632.2009.04544.x

Frith, U., \& Frith, C. D. (2003). Development and neurophysiology of mentalizing. Philosophical transactions of the Royal Society of London. Series B, Biological sciences, 358(1431), 459-473. https://doi.org/10.1098/rstb.2002.1218

Gazzaniga, M. S. (2005). The ethical brain. Dana Press.

Goldberg, P. (1968). Are women prejudiced against women?. Trans-action 5, 2830. https://doi.org/10.1007/BF03180445

Gray, H. M., Gray, K., \& Wegner, D. M. (2007). Dimensions of mind perception. Science, 315(5812), 619. https://doi.org/10.1126/science.1134475

Greenwald, A. G., \& Banaji, M. R. (1995). Implicit social cognition: Attitudes, self-esteem, and stereotypes. Psychological Review, 102(1), 4-27. https://doi.org/10.1037/0033295X.102.1.4

Hacking, I. 1995b. The looping effects of human kinds. In D. Sperber \& A. J. Premack (Eds.), Causal Cognition (pp. 351-382). Oxford: Clarendon Press. 
Harris, L. T., Todorov, A., \& Fiske, S. T. (2005). Attributions on the brain: neuro-imaging dispositional inferences, beyond theory of mind. NeuroImage, 28(4), 763769. https://doi.org/10.1016/j.neuroimage.2005.05.021

Haslam, N. (2006). Dehumanization: An Integrative Review. Personality and Social Psychology Review, 10(3), 252-264. https://doi.org/10.1207/s15327957pspr1003_4

Henriques, J., Hollway, W., Couze Venn, C. U., Walkerdine, V. (1984). Changing the subject: psychology, social regulation and subjectivity. London and New York: Routledge.

Hepburn, A., \& Wiggins, S. (Eds.). (2007). Discursive research in practice: New approaches to psychology and interaction. Cambridge University Press.

Jetten, J., Haslam, C., \& Haslam, S. A. (Eds.). (2012). The social cure: Identity, health and well-being. Psychology Press.

Keil, F. C. (1999). Cognition, content, and development. In M. Bennett (ed.), Developmental psychology: Achievements and Prospects (pp. 165-184). London: Psychology Press.

Kleiman, T., Hassin, R. R., \& Trope, Y. (2014). The control-freak mind: stereotypical biases are eliminated following conflict-activated cognitive control. Journal of experimental psychology. General, 143(2), 498-503. https://doi.org/10.1037/a0033047

Kohlberg, L. (1981). The philosophy of moral development: Moral stages and the Idea of justice. San Francisco: Harper \& Row.

Kraus C. (2012) Linking Neuroscience, Medicine, Gender and Society through Controversy and Conflict Analysis: A "Dissensus Framework" for Feminist/Queer Brain Science Studies. In: R. Bluhm, A. J Jacobson, \& H. L Maibom (eds) Neurofeminism. New Directions in Philosophy and Cognitive Science (pp. 193-215). Palgrave Macmillan, London. https://doi.org/10.1057/9780230368385_10

Kruijver, F. P., Zhou, J. N., Pool, C. W., Hofman, M. A., Gooren, L. J., \& Swaab, D. F. (2000). Male-to-female transsexuals have female neuron numbers in a limbic nucleus. The Journal of clinical endocrinology and metabolism,85(5), 20342041. https://doi.org/10.1210/jcem.85.5.6564

Laing, R. D. (1960). The divided self. Penguin.

Lamb, S., \& Koven, J. (2019). Sexualization of Girls: Addressing Criticism of the APA Report, Presenting New Evidence. SAGE Open. https://doi.org/10.1177/2158244019881024 
Laughland, F. J. (2017). Paul Ricoeur's Hermeneutics of the Self: Living in the Truth (Doctoral dissertation, Duquesne University). Retrieved from https://dsc.duq.edu/etd/176

Lawrence, A. A. (2010). Sexual orientation versus age of onset as bases for typologies (subtypes) for gender identity disorder in adolescents and adults. Archives of Sexual Behaviour, 39, 514-545 (2010). https://doi.org/10.1007/s10508-009-9594-3

Ledoux, J. (2002). The self and the brain. Prospect. Retrieved from: https://www.prospectmagazine.co.uk/magazine/theselfandthebrain

Luhrmann, T. M., \& Marrow, J. (2016). Our most troubling madness: Case studies in Schizophrenia across cultures. Oakland: University of California Press.

Majid, D. A., Burke, S. M., Manzouri, A., Moody, T. D., Dhejne, C., Feusner, J. D., \& Savic, I. (2020). Neural systems for own-body processing align with gender identity rather than birth-assigned sex. Cerebral Cortex, 30(5), 2897-2909.

Matheson, K., \& Anisman, H. (2012). Biological and psychosocial responses to discrimination. In J. Jetten, C. Haslam, \& S. A. Haslam (Eds.), The social cure: Identity, health and well-being (pp. 133-153). Psychology Press.

Mead, G. H., \& da Silva, F. C. (2011). GH Mead: a reader. New York: Routledge.

Mitchell J. P. (2008). Activity in right temporo-parietal junction is not selective for theory-ofmind. Cerebral cortex (New York, N.Y. : 1991), 18(2), 262271. https://doi.org/10.1093/cercor/bhm051

Money, J., \& Ehrhardt, A. A. (1972). Man and woman, boy and girl: Differentiation and dimorphism of gender identity from conception to maturity. Johns Hopkins U. Press.

Monteith, M. J., Ashburn-Nardo, L., Voils, C. I., \& Czopp, A. M. (2002). Putting the brakes on prejudice: On the development and operation of cues for control. Journal of Personality and Social Psychology, 83(5), 1029-1050. https://doi.org/10.1037/00223514.83.5.1029

Moscovici, S. (2001). Why a theory of social representation? In K. Deaux \& G. Philogène (Eds.), Representations of the social: Bridging theoretical traditions (pp. 8-35). Blackwell Publishing.

Muuss R. E. (1988). Carol Gilligan's theory of sex differences in the development of moral reasoning during adolescence. Adolescence, 23(89), 229-243. 
Northoff, G., Heinzel, A., De Greck, M., Bermpohl, F., Dobrowolny, H., \& Panksepp, J. (2006). Self-referential processing in our brain - a meta-analysis of imaging studies on the self. Neuroimage, 31(1), 440-457.

Popper, K. R. (1968). The logic of scientific discovery. New York: Harper \& Row.

Prabhu, P. H. (1991). Hindu social organization: A study in socio-psychological and ideological foundations. Popular Prakashan.

Putnam, H. (1981). Reason, truth and history. Cambridge: Cambridge University Press.

Reimer, N. K., Kamble, S. V., Schmid, K., \& Hewstone, M. (2020). Intergroup contact fosters more inclusive social identities. Group Processes \& Intergroup Relations. https://doi.org/10.1177/1368430220960795

Richards, G. (2009). Putting psychology in its place: Critical historical perspectives. Routledge.

Rippon, G. (2019). The gendered brain: The new neuroscience that shatters the myth of the female brain. UK: Penguin Random House.

Shotter, J. (2011). Embodiment, abduction, and expressive movement: A new realm of inquiry? Theory \& $\quad \& \quad$ Psychology, 21(4), 439456. https://doi.org/10.1177/0959354310372992

Smith, A. M. (2004). Human action, neuroscience and the law. In D. Rees \& S. Rose (Eds.), The new brain sciences: Perils and Prospects (pp. 103-122). Cambridge: Cambridge University press.

Stam, H. J. (Ed.). (1998). The body and psychology. Sage.

Teo, T. (2015). Critical psychology: A geography of intellectual engagement and resistance. American Psychologist, 70(3), 243.

Tipler, C. N., \& Ruscher, J. B. (2019) Dehumanizing representations of women: the shaping of hostile sexist attitudes through animalistic metaphors. Journal of Gender Studies, 28 (1), 109-118, DOI: 10.1080/09589236.2017.1411790

Vaes, J., Paladino, P., \& Puvia, E. (2011). Are sexualized women complete human beings? Why men and women dehumanize sexually objectified women. European Journal of Social Psychology, 41(6), 774-785. https://doi.org/10.1002/ejsp.824

van Mourik Broekman, A., Koudenburg, N., Gordijn, E. H., Krans, K. L. S., \& Postmes, T. (2019). The impact of art: Exploring the social-psychological pathways that connect 
audiences to live performances. Journal of Personality and Social Psychology, 116(6), 942-965. https://doi.org/10.1037/pspi0000159

Vidal, F. (2009). Brainhood, anthropological figure of modernity. History of the Human Sciences, 22(1), 5-36. https://doi.org/10.1177/0952695108099133

Vocks, S., Busch, M., Grönemeyer, D., Schulte, D., Herpertz, S., \& Suchan, B. (2010). Differential neuronal responses to the self and others in the extrastriate body area and the fusiform body area. Cognitive, Affective, \& Behavioral Neuroscience, 10(3), 422429.

Waytz, A., Epley, N., \& Cacioppo, J. T. (2010). Social cognition unbound: Insights into anthropomorphism and dehumanization. Current Directions in Psychological Science, 19(1), 58-62.

Wilkes, K. V. (1988). Real people: Personal identity without thought experiments. Oxford: Oxford University Press.

Zhou, J. N., Hofman, M. A., Gooren, L. J., \& Swaab, D. F. (1995). A sex difference in the human brain and its relation to transsexuality. Nature, 378(6552), 6870. https://doi.org/10.1038/378068a0

Zhu, Y., Zhang, L., Fan, J., \& Han, S. (2007). Neural basis of cultural influence on selfrepresentation. Neuroimage, 34(3), 1310-1316. 